RESEARCH REPORT

\title{
Cognitive performance in childhood and early adult illness: a prospective cohort study
}

\author{
Laurie T Martin, Garrett M Fitzmaurice, Daniel J Kindlon, Stephen L Buka
}

J Epidemiol Community Health 2004;58:674-679. doi: 10.1136/jech.2003.016444

See end of article for authors' affiliations

.....................

Correspondence to:

Dr L T Martin, Department of Epidemiology, Harvard School of Public Health,

Kresge Building 602, 677 Huntington Avenue,

Boston, MA 02115, USA;

Ithayer@hsph.harvard.edu

Accepted for publication 18 December 2003

\begin{abstract}
Study objective: To evaluate whether cognitive performance in childhood is an early determinant of adult illness.

Design: Prospective cohort study covering over 30 years.

Setting: Providence, Rhode Island, USA.

Participants: 633 people ages 30-39 followed up since birth as part of the Providence cohort of the national collaborative perinatal project.

Main results: Higher cognitive performance at age 7 was related to a significantly reduced risk of serious illness in adulthood, $\mathrm{OR}=0.65(95 \% \mathrm{Cl}$ : 0.47 to 0.89$)$ for a one standard deviation ( 15 point) increase in IQ score. This association was independent of both parental socioeconomic status and participant's attained level of education.

Conclusions: General cognitive performance may be an important and informative early determinant of adult health. Further evaluation of this association and mechanisms linking cognitive performance and health may provide new and innovative strategies to improve disease management and reduce morbidity.
\end{abstract}

O ver the past decade there has been a shift in thinking about the causes and prevention of illness in adulthood. Experiences throughout the life course, and in particular experiences in early life including birth weight, ${ }^{1}$ fetal growth, ${ }^{2}$ and socioeconomic status ${ }^{3}$ have gained prominence as determinants of adult health. ${ }^{4}$

Evidence has recently emerged suggesting that general cognitive performance in childhood may be an important early determinant of adult health as well. For example, studies show that people with higher cognitive functioning late in life had a reduced risk of mortality. ${ }^{5}$ Furthermore, a similar association between mortality risk and cognitive functioning is found when cognitive performance is measured in childhood..$^{6-8}$ However, we are not aware of any studies that evaluated whether cognitive performance in childhood is associated with morbidity earlier in the life course.

Research findings across diverse disciplines suggest that the link between intelligence and health is an important, yet untapped, area of research. ${ }^{9}$ Understanding the association between cognitive performance and health may provide new and innovative strategies to improve disease management and reduce morbidity. This study evaluates the hypothesis that an advantage in cognitive performance in childhood is associated with a lower risk of serious illness in adulthood, independent of socioeconomic status in both childhood and adulthood.

\section{METHODS}

\section{Study sample}

Subjects were offspring of mothers enrolled in the Providence, Rhode Island site of the national collaborative perinatal project (NCPP; described in detail by Niswander and Gordon $^{10}$ ). Briefly, the NCPP was a multi-site cohort study that involved the prospective observation and examination of over 50000 pregnancies through the first seven years of life in 12 cities across the United States. In the Providence site, 4140 pregnancies were enrolled between 1959 and 1966.

In 1996, when subjects were in their early 30s, 1062 people in the Providence cohort were selected for a follow up study.
This follow up study was carried out with a specific interest in evaluating the long term outcomes of people with learning disabilities as children. All participants in the Providence cohort with a learning disability at age 7 were selected for follow up $(\mathrm{n}=452)$ and 610 people without learning disabilities were also randomly selected. All subjects selected for follow up had a full scale IQ (FSIQ) greater than or equal to 80 at age seven. ${ }^{11}$ People with a FSIQ less than 80 were excluded because the FSIQ score is outside of what is viewed as the normal range for the general population, ${ }^{12}$ and there is no consensus on how to diagnose learning disabilities in people with a very low IQ. ${ }^{13}$ During the adult interview, participants completed several neuropsychological tasks and provided information on a variety of domains about themselves and their families.

\section{Health status}

During the follow up interview, information was collected on nine conditions representing a range of illnesses that can be considered serious. In a similar format to the national health and nutrition examination survey epidemiologic follow up study ${ }^{14}$ subjects were asked "Have you ever been told by a physician/osteopath that you had...?" Diseases included heart disease, diabetes, cancer, asthma, arthritis, stroke, bleeding ulcer, tuberculosis, and hepatitis. Subjects who answered "yes" to any of the questions were then asked their age at first diagnosis. Because participants were comparatively young and the prevalence of each illness was low, a dichotomous measure was created indicating the presence of any of the above conditions.

\section{Cognitive performance}

Children enrolled in the NCPP were evaluated throughout the first seven years of life on a wide range of neurological, cognitive, developmental, and behavioural measures. Cognitive performance at age 7 was assessed using the

Abbreviations: SES, socioeconomic status; NCPP, national collaborative perinatal project; FSIQ, full scale IQ; GED, general educational development degree; LBW, low birth weight 
Wechsler intelligence scale for children, ${ }^{15}$ which provided an estimate of each child's FSIQ. The mean FSIQ in this sample was 99.0 with a standard deviation (SD) of 12.2. In the general population, the mean FSIQ is 100 with a standard deviation of 15 .

\section{Learning disability}

People were classified as having a learning disability at age 7 if their achievement on standardised tests of reading, spelling, or arithmetic was much lower than would be expected given their general level of cognitive performance. The magnitude of the discrepancy between a child's general intelligence and academic performance was estimated by calculating the ratio of a person's standard score on each subtest of the wide range achievement test ${ }^{16}$ in comparison with their FSIQ. Within each of four strata of cognitive performance (FSIQ 80-89, 90-99, 100-109, 110+), people were identified as having a learning disability if their ratio score for reading, spelling, or arithmetic was in the bottom $6.7 \%$ (1.5 SD) of ratios for that subtest. ${ }^{11}$ Of 720 subjects interviewed in adulthood, 305 were identified as having a learning disability in childhood.

\section{Sociodemographic measures}

Socioeconomic status (SES) at age 7 was measured by a composite index adapted from the United States Bureau of the Census that averaged centiles derived from the education and occupation of the head of the household, as well as family income. ${ }^{17}$ SES at age 7 was a continuous measure ranging from 0.3-9.7, with 9.7 indicating the highest SES.

Adult SES was measured using attained level of education. Education level was chosen because it is fairly stable across time, and more importantly, probably completed before the onset of illness. Although alternate measures of adult SES were assessed during the adult interview, they are more likely to be influenced by a significant change in health status. Educational attainment was categorised into five groups: less than high school, a general educational development degree (GED), high school graduate, some schooling beyond high school, and college graduate or higher. A GED is a high school equivalency degree obtained by subjects who did not graduate from high school.

\section{Analysis}

Multiple logistic regression was used to evaluate the relation between cognitive performance at age 7 and presence of an illness in adulthood. All multivariate models controlled for sex, race (white/non-white), SES at age 7, low birth weight (LBW), and learning disabled at age 7 . Low birth weight was included to account for the association between birth weight and lower FSIQ, ${ }^{18}$ as well as the possibility that adult health was negatively affected by poor growth in utero. ${ }^{19}$ Although certain illnesses are associated with birth weight across the continuum, treatment of birth weight as a continuous variable did not change the results. People were considered LBW if their weight was $<2500$ grams at birth.

Table 1 Characteristics of National Collaborative Perinatal Project (NCPP) participants selected for follow up, interviewed, and included in the analytical sample

\begin{tabular}{|c|c|c|c|}
\hline Characteristics & $\begin{array}{l}\text { Selected for follow up (\%) } \\
n=1062\end{array}$ & $\begin{array}{l}\text { Full interviewed sample (\%) } \\
n=720\end{array}$ & $\begin{array}{l}\text { Analytical sample (\%) } \\
n=633\end{array}$ \\
\hline \multicolumn{4}{|l|}{ Any illness } \\
\hline Yes & - & - & 17.5 \\
\hline No & - & - & 82.5 \\
\hline \multicolumn{4}{|l|}{ Self perceived health } \\
\hline Excellent & - & - & 32.2 \\
\hline Good & - & - & 45.0 \\
\hline Fair & - & - & 18.4 \\
\hline Poor & - & - & 4.4 \\
\hline \multicolumn{4}{|l|}{ Full scale $I Q$, age 7} \\
\hline $80-89$ & 28.8 & 24.7 & 23.7 \\
\hline $90-99$ & 34.4 & 33.1 & 33.6 \\
\hline $100-109$ & 23.3 & 25.4 & 25.8 \\
\hline $110+$ & 13.5 & 16.8 & 16.9 \\
\hline \multicolumn{4}{|l|}{ Sex } \\
\hline Male & 64.5 & 61.3 & 61.1 \\
\hline Female & 35.5 & 38.8 & 38.9 \\
\hline \multicolumn{4}{|l|}{ Race } \\
\hline White & 77.8 & 77.1 & 77.9 \\
\hline \multirow{2}{*}{\multicolumn{4}{|c|}{ Low birth weight* }} \\
\hline & & & \\
\hline Yes & 9.3 & 10.1 & 9.9 \\
\hline No & 90.7 & 89.9 & 90.1 \\
\hline \multicolumn{4}{|l|}{ Learning disability } \\
\hline Yes & 42.6 & 42.4 & 42.5 \\
\hline No & 57.4 & 57.6 & 57.5 \\
\hline \multicolumn{4}{|l|}{ Socioeconomic status, } \\
\hline $\begin{array}{l}\text { Lowest quartile } \\
(0.2-2.5)\end{array}$ & 23.5 & 24.2 & 23.8 \\
\hline Middle-low $(2.6-4.0)$ & 27.3 & 25.6 & 24.8 \\
\hline Middle-high (4.1-5.6) & 23.2 & 23.1 & 24.5 \\
\hline Highest quartile & 22.3 & 23.2 & 22.9 \\
\hline \multicolumn{4}{|l|}{ Attained education } \\
\hline$<$ High school & - & 18.2 & 17.5 \\
\hline GED $\ddagger$ & - & 14.4 & 13.9 \\
\hline High school graduate & - & 19.9 & 20.7 \\
\hline Beyond high school & - & 35.4 & 35.2 \\
\hline College degree or more & - & 12.1 & 12.6 \\
\hline
\end{tabular}


Logistic regression coefficients were multiplied by 15 and then exponentiated to obtain odds ratios (OR) that correspond to a 15 point ( $1 \mathrm{SD}$ ) difference in childhood FSIQ. Interaction terms between FSIQ and sex, race, and SES at age 7 were considered, but were not included in the final models as they were not statistically significant.

\section{RESULTS}

Of 1062 subjects selected for follow up in adulthood, 47 had died or were otherwise ineligible, and 295 subjects were not assessed. Overall, 720 (70.9\%) of the surviving 1105 subjects selected for follow up were successfully located and completed an interview (for further description see Buka, et al, $1998^{11}$ ). Significantly more women and people with higher IQ were interviewed, however, no difference was found in terms of race/ethnicity, low birth weight, or SES at age 7 (see table 1). There was no statistically significant difference in FSIQ between those who died and those who survived to the start of the follow up.

An additional 87 subjects were excluded from the analytical sample, 13 because they did not provide responses to the health related questions, and 74 because they reported an illness of interest diagnosed before their 18th birthday. This last group was excluded to ensure that the measure of cognitive performance preceded the onset of disease, as many illnesses are known to affect cognitive performance in subclinical form. ${ }^{20}$ Our interest in the effect of adult socioeconomic status in the association between IQ and illness also necessitated excluding these subjects to avoid the possibility of "health selection," whereby a person's health influences social position. ${ }^{22}$ Removing these subjects left an analytical sample of 633 people. Of those who were interviewed, there were no significant differences on any variables of interest, including sex, race, SES at age 7, LBW, or FSIQ at age 7, between the 633 subjects retained for the analysis and the 87 excluded.

\section{Presence of a diagnosed illness in adulthood}

In adulthood, subjects were between the ages of 30-39, with a mean age of $33.6(\mathrm{SD}=1.8)$. Overall, the prevalence of each illness in adulthood was low, ranging from $0.6 \%$ (tuberculosis) to $5.2 \%$ (asthma). No cases of stroke were reported. Subjects were, on average, 27.5 years old at the time of their first diagnosis $(S D=4.9)$, with mean age of adult onset ranging from 25.5 for tuberculosis to 29.4 for heart disease. To determine whether the prevalence of each illness in this study was consistent with that reported in the general population, we obtained general population prevalence figures from national sources such as the National Center for Health Statistics and the SEER Cancer Registry. ${ }^{23-25}$ We calculated the prevalence and 95\% confidence intervals (CI) for each illness in our sample. For 9 of the 10 comparisons (90\%), the $95 \%$ CI for our analytical sample covered the general population estimates (results not shown). There was a slightly larger proportion of subjects with diabetes in our sample compared with the general population. The prevalence and 95\% confidence interval was also calculated for each illness in our sample for men, women, white people, and non-white people separately. Overall, these were consistent with national prevalence figures for individuals of similar demographics.

Table 2 shows univariate associations between FSIQ at age 7 and (a) any illness, (b) each illness individually, and (c) total number of illnesses. There was an inverse gradient between FSIQ at age 7 and illness, with the prevalence of illness lowest for those with a high FSIQ in childhood. Furthermore, this pattern appeared to be general and not limited to a specific illness. A larger proportion of people with a lower FSIQ in childhood also reported multiple illnesses in adulthood compared with those with a higher FSIQ.

Table 3 shows the results of two multiple regression models predicting the presence of any diagnosed illness in adulthood. As hypothesised, FSIQ significantly predicted health independent of sex, race, SES at age 7, LBW, and learning disabilities at age 7. A 15 point (1 SD) higher score in FSIQ was associated with a one third lower odds of illness $(\mathrm{OR}=0.65,95 \% \mathrm{CI}: 0.47$ to 0.89$)$.

When attained education level was added to the model, the effect size of FSIQ remained significant and consistent with the previous analysis (OR $=0.67$ (95\%CI: 0.48 to 0.95 ) for a one SD increase in FSIQ), suggesting that the association between FSIQ and health was not fully explained by adult SES.

While educational attainment has advantages in that it is fairly stable across the life course and probably completed before the onset of illness, it can be argued that level of education is both strongly determined by, and a marker for, childhood social position and therefore not the best measure

Table 2 Relation between cognitive performance at age 7 and health outcomes in adulthood $(n=633)$

\begin{tabular}{|c|c|c|c|c|c|}
\hline \multirow[b]{2}{*}{ Health outcomes } & \multicolumn{5}{|c|}{ Full scale $I Q$ at age 7} \\
\hline & Number (\%) & $\begin{array}{l}80-89(\%) \\
n=150\end{array}$ & $\begin{array}{l}90-99(\%) \\
n=213\end{array}$ & $\begin{array}{l}100-109(\%) \\
n=163\end{array}$ & $\begin{array}{l}110+(\%) \\
n=107\end{array}$ \\
\hline Total & 633 & 23.7 & 33.6 & 25.8 & 16.9 \\
\hline \multicolumn{6}{|l|}{ Any illness* } \\
\hline Yes & $111(17.5)$ & 22.0 & 18.8 & 16.6 & 10.3 \\
\hline No & $522(82.5)$ & 78.0 & 81.2 & 83.4 & 89.7 \\
\hline \multicolumn{6}{|l|}{ Diagnosed illness* } \\
\hline Arthritis & 21 (3.3) & 5.3 & 6.1 & 6.1 & 1.9 \\
\hline Asthma & $33(5.2)$ & 4.0 & 3.8 & 3.7 & 0.9 \\
\hline Bleeding ulcer & $10(1.6)$ & 2.0 & 1.4 & 0.6 & 2.8 \\
\hline Cancer & $14(2.2)$ & 3.3 & 2.8 & 1.8 & 0.0 \\
\hline Diabetes & $16(2.5)$ & 5.3 & 2.8 & 0.6 & 0.9 \\
\hline Heart disease & $14(2.2)$ & 2.7 & 1.9 & 1.8 & 2.8 \\
\hline Hepatitis & 19 (3.0) & 4.0 & 2.8 & 3.1 & 1.9 \\
\hline Tuberculosis & $4(0.6)$ & 0.7 & 0.5 & 1.2 & 0.0 \\
\hline \multicolumn{6}{|c|}{ Number of illnesses } \\
\hline 0 & $522(82.5)$ & 78.0 & 81.2 & 83.4 & 89.7 \\
\hline 1 & $96(15.2)$ & 18.7 & 16.4 & 14.1 & 9.3 \\
\hline 2 & $10(1.6)$ & 1.3 & 1.4 & 2.4 & 0.9 \\
\hline 3 & $5(0.8)$ & 2.0 & 0.9 & 0.0 & 0.0 \\
\hline
\end{tabular}




\begin{tabular}{|c|c|c|c|c|}
\hline \multirow[b]{2}{*}{ Characteristics } & \multicolumn{2}{|c|}{ Without educational attainment } & \multicolumn{2}{|c|}{ With educational attainment } \\
\hline & $\begin{array}{l}\text { Adjusted odds } \\
\text { ratio }\end{array}$ & $95 \% \mathrm{Cl}$ & $\begin{array}{l}\text { Adjusted odds } \\
\text { ratio }\end{array}$ & $95 \% \mathrm{Cl}$ \\
\hline $\begin{array}{l}\text { Full scale IQ, age } 7 \ddagger \\
\text { Female } \\
\text { White } \\
\text { SES, age } 7 \S \\
\text { Low birth weight } \\
\text { Learning disability, age } 7 \\
\text { Attained education } \\
\text { < High school } \\
\text { GEDt† } \\
\text { High school graduate } \\
\text { Beyond high school } \\
\text { College degree or more }\end{array}$ & $\begin{array}{l}0.65^{* *} \\
2.52^{\star *} \\
2.21^{* *} \\
0.92 \\
0.79 \\
1.52\end{array}$ & $\begin{array}{l}(0.47 \text { to } 0.89) \\
(1.62 \text { to } 3.91) \\
(1.22 \text { to } 3.98) \\
(0.72 \text { to } 1.19) \\
(0.37 \text { to } 1.67) \\
(0.98 \text { to } 2.36)\end{array}$ & $\begin{array}{l}0.67^{*} \\
2.50^{* *} \\
2.25^{* *} \\
0.95 \\
0.82 \\
1.52 \\
\\
1.29 \\
1.40 \\
0.57 \\
1.03 \\
\text { reference }\end{array}$ & $\begin{array}{l}(0.48 \text { to } 0.95) \\
(1.60 \text { to } 3.90) \\
(1.24 \text { to } 4.08) \\
(0.73 \text { to } 1.23) \\
(0.38 \text { to } 1.76) \\
(0.97 \text { to } 2.38) \\
(0.49 \text { to } 3.40) \\
(0.54 \text { to } 3.61) \\
(0.22 \text { to } 1.49) \\
(0.45 \text { to } 2.37) \\
-\end{array}$ \\
\hline $\begin{array}{l}\text { †Twenty five participants } \\
\text { point) higher FSIQ. §Corr } \\
\text { †TGeneral education deve }\end{array}$ & $\begin{array}{l}\text { sing data for } \\
\text { to a } 1 \mathrm{SD} \text { in } \\
\text { t degree (higl }\end{array}$ & $\begin{array}{l}\text { cioeconomic st } \\
\text { ease in SES at } \\
\text { school equival }\end{array}$ & $\begin{array}{l}\text { S) at age } 7 . \mp \\
\text { 'Birth weight } \\
<0.05 ;{ }^{* *} p<C\end{array}$ & $\begin{array}{l}\text { esponds to a } 1 \text { SD }(15 \\
\text { than } 2500 \text { grams. }\end{array}$ \\
\hline
\end{tabular}

of adult social circumstances. ${ }^{26}$ We re-evaluated our hypothesis using adult occupational class as the measure of adult SES, rather than educational attainment. Three categories of occupational class were created based on US census codes: unskilled/semi-skilled manual, skilled manual, and nonmanual. The odds of having an illness in adulthood for people in the unskilled/semi-skilled and skilled manual occupational classes were 2.11 (95\%CI: 1.07 to 4.13 ) and 1.67 (95\%CI: 0.88 to 3.15 ) greater compared with those in nonmanual occupations respectively. However, the effect size of FSIQ remained significant (OR $=0.70$ (95\%CI: 0.51 to 0.98 ) for a one SD increase in FSIQ), again suggesting that the association between FSIQ and health was not fully explained by adult social position.

Multivariate associations between FSIQ and each illness individually were also evaluated, with the exception of tuberculosis, which was only reported by four subjects. All odds ratios for a 15 point increase in FSIQ were less than one, ranging from 0.31 (diabetes) to 0.98 (bleeding ulcer and heart disease). Only the association with diabetes was significant. In a linear regression model predicting the number of illnesses reported in adulthood, each 1 SD increase in FSIQ was associated with a lower number of illnesses $(\beta=-0.07$, $\mathrm{SE}=0.03, \mathrm{p}=0.01$ ).

Because our outcome was based on self reported illness, we evaluated whether our results were influenced by reporting bias. According to the literature, heart disease, cancer, and diabetes are the most accurately reported by self report. ${ }^{27} 28$ Therefore, we repeated the original analysis using the presence of any of these three illnesses as the outcome. After accounting for sex, race, SES at age 7, LBW, and learning disability at age 7 , the odds of a physician diagnosis of heart disease, cancer, or diabetes was 0.53 (95\%CI: 0.32 to 0.88 ) for a one SD higher score in FSIQ.

\section{DISCUSSION}

Results of this study provide a unique contribution to the life course literature, ${ }^{62}$ suggesting that cognitive performance in childhood, measured by FSIQ, has long term effects on morbidity. This is one of the first papers to examine this relation in a comparatively young adult population. A 15 point increase in FSIQ at age 7 reduced the odds of illness in adulthood by about a third.

This association was independent of SES in both childhood and adulthood, regardless of whether attained education or occupational class was used as the measure of adult SES. Given that SES in childhood influences both cognitive performance and health status ${ }^{30}$ it can be argued that a more sophisticated measure of SES might modify the relation between FSIQ and adult health. SES at both birth and age 7 were collected in the NCPP and were examined independently (that is, income, education, occupation) and in combination to identify the most powerful predictor of later health status. An index of the parent's SES when the child was 7 was the best predictor and was therefore used in these analyses. Existing research has similarly shown that intelligence in childhood is an independent, and potentially stronger predictor of later outcomes than childhood SES. ${ }^{31}{ }^{32}$

Strengths of this study include its large, community sample of children followed up over three decades and our ability to establish the temporal nature of the association of interest. Cognitive performance was measured at age 7 , on average 21 years before the onset of illness, eliminating the concern often present in studies of elderly populations that the illness caused a decline in cognitive function. ${ }^{33}$ While it could be argued that other early life factors may exist to further modify the association, another strength of this study is that these analyses accounted for both fetal growth and childhood SES, two factors known to influence both cognitive performance and health. A final strength of this study is that the prevalence of each illness in our sample was consistent with national prevalence figures in individuals of a similar age, suggesting that the illnesses were accurately reported. Furthermore, the association between cognitive performance and morbidity remained when the outcome was

\section{Key points}

- People with lower cognitive performance in childhood are at increased risk for serious illness in adulthood, suggesting that childhood cognitive performance is an early determinant of adult health.

- Socioeconomic status in adulthood does not fully mediate the association between cognitive performance in childhood and adult health. Both childhood cognitive performance and socioeconomic status in adulthood are independent predictors of illness in adulthood.

- The relation between childhood cognitive performance and adult illness seems to be general, and not limited to a specific illness or set of illnesses. 
limited to three illnesses shown to be accurately reported in the literature.

One limitation to this analysis is that information on illnesses other than the nine evaluated was not available. Because this study focused on the presence of major illness in adulthood, additional research is needed to evaluate whether cognitive performance is associated with other health outcomes, including those considered less serious.

While the outcome of this study was limited to illnesses diagnosed after the age of 18 , we evaluated whether this restriction biased the results. The association between cognitive performance and any illness diagnosed on or after age 8 (continuing to exclude those whose illness preceded the age 7 cognitive assessment), remained significant. A 15 point higher FSIQ at age 7 was significantly associated with a decrease in the odds of illness diagnosed on or after age 8 ( $\mathrm{OR}=0.72$ 95\%CI: 0.54 to 0.95 ).

The generalisability of these findings should not be affected by the demographics of the sample. A large proportion of the national sample for the NCPP pregnancies was enrolled through public clinics and as a result, the study sample is skewed toward the lower socioeconomic levels. However, the skewnesss has been shown to be small ${ }^{11}$ and in Providence, about 15\% of the sample was enrolled through private obstetricians further increasing the representativeness of this cohort. ${ }^{11}{ }^{34}$ This sample, however, was limited to people with a FSIQ of 80 or higher, and the results should not be extended beyond this range.

Although a higher proportion of selected subjects with higher FSIQ scores were successfully interviewed, an informal analysis of differential attrition by IQ group found that non-interviewed people in the higher FSIQ groups would need to have a rate of illness twice that of the noninterviewed people in the lower FSIQ groups to fully mitigate the association between FSIQ and adult health.

If the association between FSIQ at age 7 and adult health is causal, key to a better understanding of this association will be the identification of mechanisms and pathways linking childhood cognitive performance and adult health. One mechanism may be that higher cognitive performance predicts health risk behaviours. There is evidence that health behaviours, such as smoking, physical fitness, diet, and alcohol use are associated with cognitive performance. ${ }^{31} 35$ Our data show that as IQ at age 7 increases, the proportion of people who report ever having smoked daily for one month or more significantly declines $\left(\chi^{2}=10.5, \mathrm{p}=0.01\right)$. However, smoking was not associated with adult illness in our sample. This is probably because smoking is not a risk factor for all illnesses included in our outcome, and because of the comparatively young age of the sample, as illnesses may not occur until several years after the start of smoking.

Functional literacy is another potential pathway by which cognitive performance affects health. Functional literacy

\section{Policy implications}

- Skills captured by tests of intelligence including verbal and written communication, memory, and numeracy are important to the successful management of a person's health. Individual skill levels should be considered when developing health promotion materials and communicating with patients.

- Further evaluation of mechanisms linking cognitive performance and adult health may provide new and innovative strategies to improve disease management and reduce morbidity across the life course. expands upon traditional literacy skills to include numeracy or quantitative skills, memory, planning, and problem solving skills. While little research has directly linked FSIQ and functional literacy, it has been argued that measures of functional literacy assess a general level of cognitive performance similar to that of intelligence tests. ${ }^{31}$ These skills are critical for the successful management of a person's health care as people are expected to read medicine labels, understand safety regulations, communicate effectively with providers, and to gain access to, and navigate healthcare systems. ${ }^{36}$

Sense of control may also contribute to the association between childhood IQ and adult health. People with a higher level of cognitive performance may feel more in control and have less of a physiological response to stressors, resulting in less wear and tear on the body and ultimately better health. ${ }^{37-39}$

The results of this study suggest that general cognitive performance may be an important and informative early determinant of health. We propose that skills captured by tests of intelligence are important to the successful management of a person's health. Replication and further evaluation of this association and mechanisms linking cognitive performance and health may provide new and innovative strategies to improve disease management and reduce morbidity across the life course.

\section{Authors' affiliations}

L T Martin, Department of Epidemiology, Harvard School of Public Health, Boston, USA

G M Fitzmaurice, Department of Biostatistics, Harvard School of Public Health

D J Kindlon, S L Buka, Department of Society, Human Development and Health, Harvard School of Public Health

Funding: support for this research was provided by the training program in psychiatric epidemiology, grant number T32 MH17119, and MCHB grant number 5T76 MC 00001 (formerly MCH201).

Conflicts of interest: none declared.

\section{REFERENCES}

1 McCormick $M$. The outcomes of very low birth weight infants: Are we asking the right questions? Pediatrics 1997;99:869-76.

2 Barker D. Mothers, babies, and health in later life. Edinburgh: Churchill Livingstone, 1998:217

3 Davey Smith G, Hart C, Blane D, et al. Lifetime socioeconomic position and mortality: prospective observational study. BMJ 1997;314:547-52.

4 Halfon N, Hochstein M. Life course health development: an integrated framework for developing health, policy and research. Milbank $Q$ 2002;80:433-79

5 Bassuk S, Wypii D, Berkman L. Cognitive impairment and mortality in the community-dwelling elderly. Am J Epidemiol 2000;151:676-88.

6 Whalley L, Deary I. Longitudinal cohort study of childhood IQ and survival up to age 76. BMJ 2001;322:819-22.

7 Hart C, Deary I, Davey Smith G, et al. Childhood IQ, social class, deprivation and their relationships with mortality and morbidity risk in later life: prospective observational study linking the Scottish Mental Survey 1932 and the Midspan studies. Psychosom Med 2003;65:877-83.

8 Osler M, Andersen A, Due P, et al. Socioeconomic position in early life, birth weight, childhood cognitive function, and adult mortality: a longitudinal study of Danish men born in 1953. J Epidemiol Community Health 2003:57:681-6.

9 Lubinski D, Humphreys L. Incorporating general intelligence into epidemiology and the social sciences. Intelligence 1997;24:59-201.

10 Niswander K, Gordon M. The women and their pregnancies. Washington DC: Government Printing Office, 1972:540.

11 Buka S, Satz P, Seidman L, et al. Defining learning disabilities: the role of longitudinal studies. Thalamus 1998;16:14-29.

12 Grunau R, Whiffield $M$, Davis C. Pattern of learning disabilities in children with extremely low birth weight and broadly average intelligence. Arch Pediatr Adolesc Med 2002;156:615-20.

13 Polloway E, Patton J, Smith T, et al. Mental retardation and learning disabilities: conceptual and applied issues. J Learn Disabil 1997;30:297-308.

14 Madans J, Kleinman J, Cox C, et al. 10 years after NHANES I: report of initial followup, 1982-84. Public Health Rep 1986;101:465-73.

15 Wechsler D. Wechsler intelligence scale for children. New York, NY: The Psychological Corporation, 1949. 
16 Jastak J, Jastak S. Wide range achievement test (WRAT). Wilmington, DE: Jastak Associates, 1978

17 Myrianthopoulos N, French K. An application of the US Bureau of the Census socioeconomic index to a large, diversified patient population. Soc Sci Med 1968:2:283-99

18 Richards $M$, Hardy R, Kuh D, et al. Birth weight and cognitive function in the British 1946 birth cohort: longitudinal population based study. BM 2001;322:199-203.

19 Barker D. Mothers, babies and disease in later life. London: BMJ Books, 1994:217.

20 Holland C, Rabbitt P. The course and causes of cognitive change with advancing age. Rev Clinic Gerontol 1991;1:81-96.

21 Starr J, Deary I, Lemmon $\mathrm{H}$, et al. Mental ability age 11 years and health status age 77 years. Age Aging 2000;29:523-8.

22 Marmot M, Ryff C, Bumpass L, et al. Social inequalities in health: next questions and converging evidence. Soc Sci Med 1997:44:901-10.

23 American Heart Association. 2001 Heart and stroke statistical update. Dallas, TX: American Heart Association, 2000:42.

24 Collins J. Prevalence of selected chronic conditions: United States 1990-1999. Rockville, MD: National Center for Health Statistics, Vital and Health Stat Series no 10, 1997:89.

25 Ries L, Eisner M, Kosary C, et al. SEER cancer statistics review, 1973-1998. Bethesda, MD: National Cancer Institute, 2001:47.

26 Davey Smith G, Hart C, Hole D, et al. Education and occupational social class: Which is the more important indicator of mortality risk? J Epidemiol Community Health 1997;52:153-60.

27 Heliovaara M, Aromaa A, Klaukka T, et al. Reliability and validity of interview data on chronic diseases. J Clin Epidemiol 1993;46:181-91.

28 Krueger D. Measurement of prevalence of chronic disease by household interviews and clinical evaluations. Am J Public Health 1957;47:953-60
29 Hart C, Deary I, Taylor M, et al. The Scottish Mental Survey 1932 linked to the Midspan studies: a prospective investigation of childhood intelligence and future health. Public Health 2003; 117:187-95.

30 Brooks-Gunn J, Duncan G, Britto P. Are socioeconomic gradients for children similar to those for adults? In: Keating D, Hertzman C, eds. Developmental health and the wealth of nations. New York: The Guilford Press, 1999:94-124.

31 Gotffredson L. Intelligence: Is it the epidemiologists' elusive "fundamental cause" of social class inequalities in health? J Pers Soc Psychol (in press)

32 Herrnstein R, Murray C. The Bell curve: intelligence and class structure in American life. New York: The Free Press, 1994:845.

33 Kelman $H$, Thomas C, Kennedy G, et al. Cognitive impairment and mortality in older community residents. Am J Public Health 1994:84:1255-60.

34 Broman S. The collaborative perinatal project: an overview. In: Mednick S, Harway M, Finello K, eds. Handbook of longitudinal research. Vol 1. Birth and child cohorts. New York: Praeger Scientific, 1984:185-235.

35 Taylor M, Hart C, Davey Smith G, et al. Childhood mental ability and smoking cessation in adulthood: prospective observational study linking the Scottish Mental Survey 1932 and the Midspan studies. J Epidemiol Community Health 2003;57:464-5.

36 Rudd R. Health and literacy: a review of the medical and public health literature. In: Comings J, Smith C, Garner B, eds. Annual review of adult learning and literacy. San Francisco: Josey-Bass, 1999:158-99.

37 Lachman M, Weaver S. The sense of control as a moderator of social class differences in health and well-being. J Pers Soc Psychol 1998;74:763-73.

38 Chou K, Chi I. Stressful life events and depressive symptoms: social support and sense of control and mediators or moderators? Int J Aging Hum Dev 2001;52:155-71.

39 Sapolsky R. Why zebras don't get ulcers: a guide to stress, stress-related diseases, and coping. New York: W H Freeman, 1994:368.

\section{THE JECH GALLERY}

\section{Small steps}

$\mathrm{H}$ eight is directly related to social class in children and adults and within each sex. ${ }^{12}$ The Small Shoe Company-the adjective referring to the shoes, not the company-reflects the small stature of local residents in the socioeconomically deprived east end of the city of Glasgow, UK. Progress to regenerate deprived urban areas has been slow. In the distance, on the south side of the River Clyde, are the failed experiments in urban planning that comprised slum clearances followed by high rise tower blocks. But behind the Small Shoe Company, the site of a former women's refuge has not yet been given a new purpose.

David S Morrison Homelessness Partnership, Greater Glasgow NHS Board, Dalian House, PO Box 15329, 350 St Vincent Street, Glasgow G3 8YZ, UK; david.morrison@gch.glasgow.gov.uk

\section{REFERENCES}

1 Power C, Manor O, Li L. Are inequalities in height underestimated by adult social position? Effects of changing social structure and height selection in a cohort study. BMJ 2002:325:131-4.

2 Walker M, Shaper AG, Wannamethee G. Height and social class in middle-aged British men. $J$ Epidemiol Community Health 1988;42:299-303.

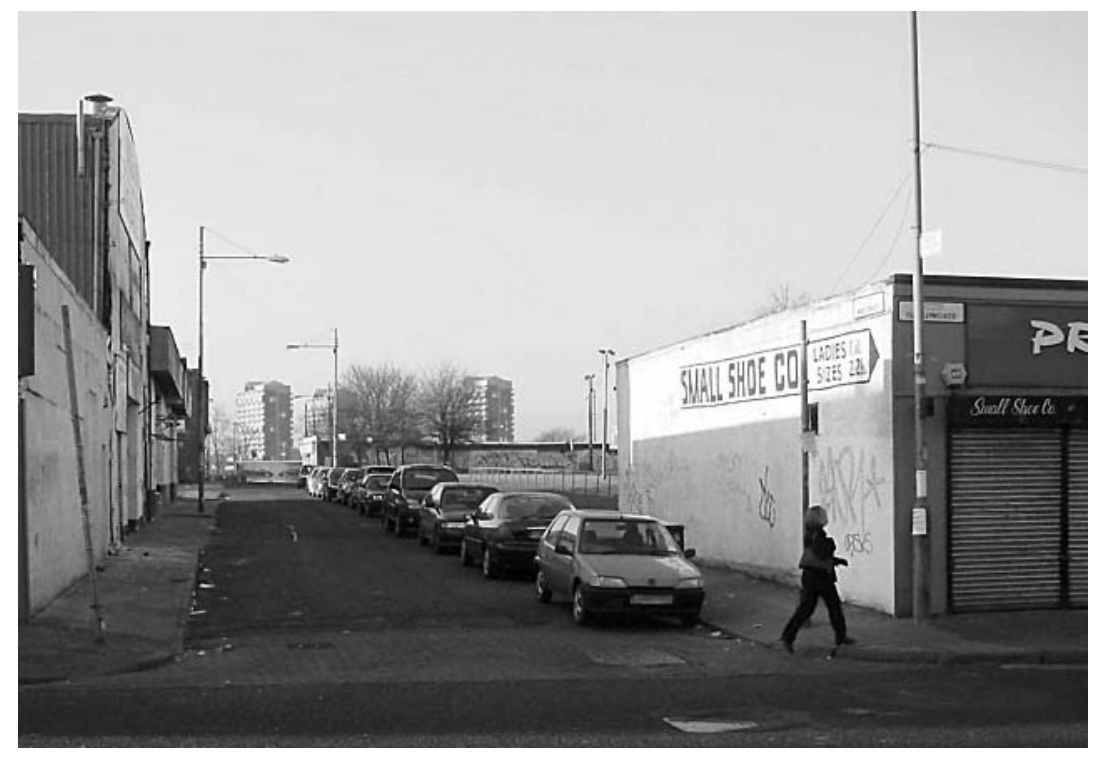

